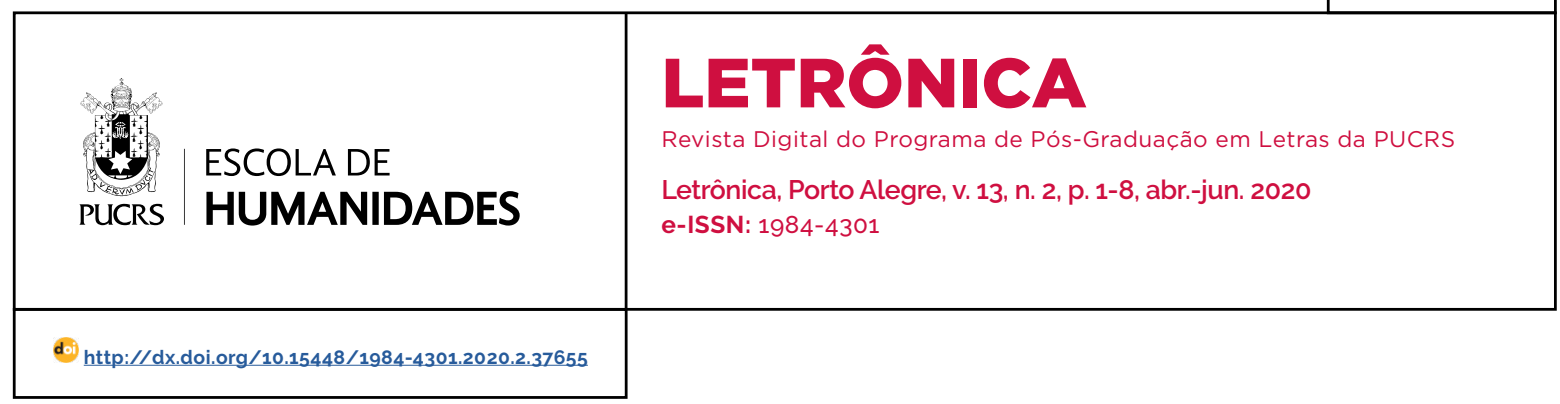

\title{
Discursos (in)tolerantes e democracia pluralista
}

(In)tolerant discourses and pluralist democracy

Discursos (in)tolerantes y democracia pluralista

Juan Manuel López-

Muñoz ${ }^{1}$

orcid.org/0000-0002-2208-2540

imanuel.lopez@uca.es

\section{Maria da Glória Corrêa di Fanti² \\ orcid.org/0000-0002-5399-5377 gloria.difanti@pucrs.br}

\section{Bárbara Luzia Covatti Malcorra ${ }^{2}$}

orcid.org/0000-0001-5710-7130 barbara.malcorra@edu.pucrs.br

Recebido em: 12 mar. 2020. Aprovado em: 13 abr. 2020 Publicado em: 13 ago. 2020.

\section{(c) (1)}

Artigo está licenciado sob forma de uma licença Creative Commons Atribuição 4.0 Internacional.
Parece haver um consenso geral a respeito da ideia de que o desenvolvimento das novas tecnologias da comunicação e, especificamente, o desenvolvimento das plataformas digitais de socialização reforçaram as tensões entre grupos, bem como a preocupação das sociedades atuais pela questão da segurança ante a propagação de discursos e práticas intolerantes (SICARD, 1998, p. 9). As instituições, públicas e privadas, estão cada vez mais sensibilizadas contra a intolerância, por temerem que ela possa desestabilizar a ordem social vigente e gerar desconfiança em relação ao consumo das novas tecnologias entre os usuários. Desse entendimento parte, sem dúvida, a motivação deste número da Letrônica, assim como da extensa literatura científica e midiática dos últimos anos sobre o tema.

Diante dessas preocupações, foram criados inúmeros observatórios dos discursos intolerantes na rede, como o da Associação Start Turning Off Prejudice Heal Attitudes Through Education (STOP HATE Crime and discrimination3), o do Proyecto Centinela para la Prevención del Genocidio4, o do Observatorio Español del Racismo y la Xenofobia 5 (OBERAXE), ou o Observatorio Proxi contra la Xenofobia y la Intolerancia en medios digitales ${ }^{6}$, para citar alguns exemplos notáveis.

Além disso, a Assembleia Parlamentar do Conselho da Europa e outras instituições supranacionais, como a Organização dos Estados Americanos, o Parlamento Europeu, a Comissão Europeia contra o Racismo e a Intolerância (ECRI), a Assembleia Geral das Nações Unidas e a Organização das Nações Unidas para a Educação, a Ciência e a Cultura, destinam, há muitos anos, esforços e fundos para a publicação de tratados internacionais, como o Convenio sobre la Ciberdelincuencia (2001), o Manual On Hate Speech (2009), a Convención Interamericana contra toda forma de discriminación e intolerancia (2013) ou, enfim, mais recente e especificamente, o manual Cómo contrarrestar el discurso de odio en línea (2015).

\footnotetext{
Universidad de Cádiz (UCA), Cádiz, Espanha.

Pontifícia Universidade Católica do Rio Grande do Sul (PUCRS), Porto Alegre, RS, Brasil.

Disponivel em: www.stophate.com/. Acesso em: 10 mar. 2020.

Disponivel em: www.hatebase.org/. Acesso em: 10 mar. 2020.

Disponivel em: www.mitramiss.gob.es/oberaxe/es/index.htm. Acesso em: 10 mar. 2020

Disponivel em: www.observatorioproxi.org/. Acesso em: 10 mar. 2020.
} 
A imprensa, o rádio e a televisão tampouco são alheios a essa responsabilidade compartilhada com os pesquisadores e as instituições (inter) nacionais perante a necessidade de destacar os pontos fortes da vida social digital e de permitir que se expressem os medos, evitando as meias verdades tanto quanto os catastrofismos ou a amplificação excessiva do fenômeno da intolerância (SICARD, 1998, p. 149-168).

Sem tirar o mérito, obviamente, de todos os esforços dos pesquisadores que nos precederam, acreditamos que a vantagem do presente número é que privilegiamos a observação e o estudo diante da convicção, contribuindo para uma maior visibilidade do sujeito anatematizado em relação ao sujeito intolerante e uma maior legitimidade (maior difusão) dos discursos tolerantes sobre os intolerantes. $O$ estudo anedótico de discursos intolerantes dá lugar aqui a estudos da (in)tolerância com uma perspectiva mais ampla, o que também permite trazer a público pesquisas sobre chaves discursivas, culturais e socioeconômicas do fenômeno, destacando certos grupos considerados historicamente como vítimas da intolerância.

Certamente, também há espaço, neste dossiê, para estudos de caso de discursos intolerantes que encontramos no atual clima de tensão social, mas levando em consideração que nenhum deles deve ser entendido como gesto intolerante isolado (IMBLEAU, 2003, p. 311). Com efeito, entendemos que um debate sobre umas caricaturas mais ou menos blasfemas ou sobre um discurso extremista, populista, a cargo de um político ou de uma pessoa influente especifica que, em determinado lugar, propaga difamações, injúrias ou propaganda discriminatória, sendo necessário, não deve distrair a atenção dos pesquisadores, por excesso de focalização microscópica, nem servir ao impulso de estratégias de limitação da liberdade de expressão.7

Com destaque, as análises que reunimos neste número, inclusive as que estão ancoradas em um discurso específico mais ou menos aparentemente criminoso, não nos distanciam do objetivo principal, que é, como entendemos, dar as chaves que permitam às sociedades se libertar dos estereótipos e padrões de comportamento (também linguísticos) ligados a relações de poder institucionalizadas ${ }^{8}$ e que estão na base da intolerância e do ódio.

A atual crise de tolerância é gerada pelas Tecnologias de Informação e Comunicação (TCls)? Podemos falar de "maior risco tecnológico" (LAGADEC, 1981), marcando uma ruptura entre a intolerância de ontem e a de hoje? Será que a gravidade do problema atualmente não tem nada em comum com o fenômeno dos discursos intolerantes anteriores ao desenvolvimento das redes sociais? Quais são as chaves socioeconômicas, culturais e políticas da intolerância hoje, dentro e fora do ciberespaço? Tais são as perguntas às quais os autores reunidos neste número tentam responder direta ou indiretamente.

Está claro que a intolerância não é um fenômeno novo, já que está vinculada a ordens sociais baseadas tradicionalmente no antagonismo (a relação entre inimigos). Mouffe (2010)9 explica que toda ordem social antagonista tem uma origem política hegemônica, baseada em práticas conjunturais que, no entanto, em um dado momento, em um determinado lugar, se estabeleceram como permanentes e foram tratadas, a seguir, como procedentes de uma ordem natural.

A intolerância pode então ser explicada como consequência da aceitação de uma ordem social como uma ordem natural. No entanto, insiste Mouffe (2010, p. 20), a ordem social sempre poderia ter sido e ainda pode ser diferente, uma vez que foi estabelecida desde sua origem a partir da exclusão de outras possibilidades. Na democracia, a ordem social nunca é a manifestação de uma ordem natural, mas sim o resultado de um acordo humano, circunstancial,

\footnotetext{
CARRILLO DONAIRE, Juan Antonio. La protección de los derechos frente a los discursos del odio: del derecho represivo a las políticas públicas antidiscriminatorias. In: ALONSO, L.; VÁZQUEZ, V. (Dir.), 2017. p. 15-38.

8 Ver, entre outros, Butler (2009, p. 47-97).

9 MOUFFE, Chantal. Politique et agonisme. Rue Descartes, v. 67, n. 1, 2010, p. 18-24. Embora o artigo não seja recente (publicado em 2010), acreditamos que possa ser muito relevante no contexto do presente dossiê e na atual situação global.
} 
portanto, trata-se de uma ordem passivel de revisão, discutível.

A ordem social baseada em antagonismos sempre pode ser desarticulada e transformada em uma ordem diferente, sustentada por uma dinâmica agonista, segundo defende Mouffe (2010). O que está em jogo na dinâmica agonista, esclarece a filósofa e cientista política belga, é a própria configuração das relações de poder que estruturam a ordem social hegemônica. Em uma confrontação agonista, os projetos opostos nunca podem ser reconciliados racionalmente, mas simplesmente aceitos em um regime que promova a tolerância e a coabitação.

A relação agonista, ${ }^{10}$ além de promover a tolerância, tem a vantagem de não precisar destruir a ordem existente nem tão pouco começar do zero, mas simplesmente recuperar os princípios de igualdade e liberdade proclamados que ainda não (ou não mais) estão sendo efetivamente utilizados pelas democracias liberais modernas.

Aplicado às interações cotidianas, entendemos que o pluralismo agonista significa que a pessoa que não compartilha nossa identidade não será considerada como um inimigo a ser derrotado, porém como um oponente cuja existência é legítima. O indivíduo intolerante poderá defender vigorosamente suas ideias e seus discursos de seu grupo dominante, contudo nunca impedirá ao individuo de um grupo dominado exercer seu direito de defender suas próprias ideias e nunca questionará a legitimidade do interlocutor.

Mouffe (2010, p. 19) especifica, nesse ponto de seu raciocínio, que é impossivel que a categoria do inimigo desapareça como tal, mas que ela é constituida por um Eles (os sujeitos intolerantes, que não respeitam os princípios democráticos básicos de igualdade e liberdade) contra um Nós (formado por grupos que, embora se oponham a Eles, não questionam os principios da democracia pluralista).

Partindo da distinção entre antagonismo (relação entre inimigos) e agonismo (relação entre opostos não inimigos), Mouffe (2010) defende a ideia de que a confrontação agonista, longe de representar um perigo para a democracia, é de fato a condição ideal para a existência de uma democracia radical, autêntica e, portanto, como acreditamos, a condição ideal para acabar com práticas intolerantes. A democracia radical implica perseguir certas formas de consenso, porém garantindo que possa ocorrer uma certa discórdia ou conflito entre Eles e Nós, de tal maneira que os cidadãos tenham a oportunidade de se expressar livremente em um clima de tolerância.

A ideia de uma identidade que seria a única apropriada para um grupo e que normalmente serve como ponto de origem dos discursos intolerantes deve ser substituida pela ideia da aceitação de uma multiplicidade de identidades que coabitam em um espaço agonista. O importante, para Mouffe (2010, p. 22), é garantir a expressão da pluralidade e evitar qualquer processo intolerante de punição, interrogatório, culpabilização ou intimidação do oponente.

Mouffe advoga uma radicalização da democracia mediante o desenvolvimento de um novo espírito democrático entre os cidadãos, baseado no compromisso permanente com uma dinâmica agonista que faça com que todas as tentativas de fechar os debates e derrotar o oponente sejam em vão, quando não impossiveis (2010, p. 23).

Mais ou menos na mesma linha, mas apontando para além da importância da pluralidade, para uma revisão da própria noção de identidade, cabe destacar o livro ${ }^{11}$ de François Jullien, intitulado /l n'y a pas d'identité culturelle (Paris, L'Herne, 2016), traduzido recentemente para o espanhol por Imanol Zubero (La identidad cultural no existe, Taurus, Madrid, 2017). Esse livro permitiria acabar com o debate da intolerância, se considerarmos, seguindo Jullien, que ela parte da premissa falaciosa da existência de identidades culturais. Conforme o filósofo, a existência de identidades coletivas diferentes umas das outras, supostamente uniformes, que estariam em situações de risco de desaparecimento ou dissolução no atual sistema

10 No artigo citado, Mouffe (2010) desenvolve o modelo de "pluralismo agonista" lque já abordou em alguns de seus livros anteriores The Democratic Paradox (2000) e On the Political (2005)]. Esse modelo se baseia na premissa da distinção entre as categorias de inimigo e oponente.

11 Veja também François Jullien (2012). 
de globalização, é uma simples crença; não é um fato. Abandonar tal premissa falsa requer, então, deixar de lado as noções de identidade e de diferença, substituindo, como propõe o autor, esta última pela noção de "intervalo" (écart) ${ }^{12}$ e aquela pela de "recursos" (ressources).

De fato, Jullien (2012) considera duas concepções possiveis de identidade: por um lado, a singular, subjetiva, que é válida em contextos conversacionais concretos (entendemos: "eu", diferente de "tu" ou "você") e, por outro lado, a coletiva, mais ou menos objetiva, de natureza cultural, que na realidade não existe ou, ao menos, não existe como um "valor" propriamente dito, articulador de um grupo, se não como um mero quadro mitológico. A vantagem do conceito jullieniano de "recursos" em vez de "identidade" é que ele permite ir além do multiculturalismo, ao estabelecer que as culturas são bens ao alcance de qualquer indivíduo, independentemente de sua origem. Os "recursos" (as supostas identidades) não são valores que exigiriam aprovação ou conversão, mas meios disponiveis para resolver uma necessidade ou executar uma determinada ação.

O autor desenvolve, ao longo do seu livro, as noções de "intervalo" (écart) e de "recurso" (ressource), as quais impedem de classificar ou de separar grupos de acordo com caracteristicas socioculturais distintas, convidando, ao contrário, a pensar sobre eles de maneira interativa e dinâmica, sujeitos a constantes mutações e transformações. Em outras palavras, as culturas são recursos, riquezas disponiveis para todos e não são valores ou quadros cognitivos de referência. São recursos que se aproveitam, se trocam, mas não se vendem nem exigem cartão de filiação. Nessa ordem de ideias, "defender" determinados recursos (certas verdades em detrimento de outras) não significa tanto protegê-los como explorá-los, colocá-los a serviço de todos os seres humanos.

Essa visão dinâmica da necessidade da inter- relação entre grupos baseada no compartilhado contrasta com a antiga visão, predominante até agora, que põe seu foco nas diferenças e nas semelhanças entre grupos. $O$ "intervalo" de Jullien não opõe dois elementos, promovendo um frente ao outro de forma antagônica, mas requer ambos os lados. O "intervalo" cria um espaço exploratório comum que permite o atrito e a comparação, porém não a exclusão. Dizendo de um modo simples, não se trata de distinguir, por exemplo, homens de mulheres, ricos de pobres, brancos de negros, colonizadores de índios, mas sim de destacar o espaço de sua relação, ou seja, de destacar o intervalo que duas partes da mesma coisa têm em comum em que cada um pode começar a entender o outro.

Essa mudança conceitual leva o autor. François Jullien, a redefinir a ideia de diálogo entre culturas, ${ }^{13}$ que deve ser entendido como um percurso e não como uma tentativa de assimilação e, em suma, que deve basear-se em exercícios de análise e não de sintese.

Por fim, voltando a essa ideia do caráter mitológico da identidade, que mencionamos anteriormente, podemos concordar com Moulay e Rebischung (2011, p. 3-5) que entendem a intolerância ao suposto inimigo como uma reação emocional diante das diferenças e que o medo e o ódio resultantes são emoções que não estão associadas a uma experiência vivida, mas a um boato ou a uma crença mais ou menos difundida. Ou seja, a intolerância pode ser uma resposta fisica, corporal, mais ou menos incontrolável, porém tem sua origem principalmente em uma questão mental, discursiva e cultural, ideológica e, sobretudo, mitológica (CARRERA, 2019, p. 17), sendo, por conseguinte, perfeitamente controlável. Dizemos controlável, não suprimivel, "porque aqueles que tentam suprimir [a] diversidade de mitos, exigindo que todas as pessoas vivam sob o mesmo mito, que alguns compartilham e

\footnotetext{
12 O autor emprega em francês o termo "écart" derivado do verbo "écarter", que normalmente designa a ação pela qual duas partes de uma mesma coisa se desviam mais ou menos uma da outra. Entendemos, segundo Jullien, que écart implica um entre dois, quer dizer, uma dinâmica de relação entre dois pontos ou limites dados. O tradutor para a edição em espanhol (La identidad cultural no existe, Taurus, Madrid, 2017), Imanol Zubero Beaskoetxea, propõe como equivalente o termo "brecha", que nós descartamos precisamente por suas conotações negativas (ligadas a ideias de ferida, de ruptura em uma frente de combate ou de fenda onde algo começa a perder sua segurança). 13 Veja François Jullien (2008).
} 
outros não, [se] desumanizam, [dando lugar] aos chamados totalitarismos" (CARRERA, 2019, p. 17).

Na comunicação mediada por computador ou dispositivo eletrônico, o problema dos antagonismos baseados em (falsas) identidades culturais se torna mais complexo devido à intercalação da cibercultura diante da cultura offline, cada uma com sua memória correspondente dos usos escritos e orais (LOPEZ-MUÑOZ, 2019).

Essa cibercultura é uma massa de práticas e conhecimentos compartilhados, um tecnoimaginário (BALANDIER, 1985), que transcende o linguístico e o cultural (no sentido tradicional, vinculado a uma língua materna ou adquirida), sendo constituida no dia a dia das interações na rede. Por meio da rede, interagimos de um modo diferente (ASSOULINE, 2012), com uma postura corporal diferente (SZUNDY et al., 2016, p. 356), passando de uma conversação à outra, de uma pesquisa à outra, às vezes com um objetivo concreto e às vezes não.

A diferente postura corporal não é um aspecto menor, como poderia parecer, pois as emoções têm uma importante dimensão corporal, além de afetiva e cognitiva. Dispomos de um variado código corporal/gestual para manifestar as emoções mais básicas, como o ódio e a rejeição, mas como elas se expressam no meio digital, em uma situação em que o corpo é praticamente abolido ou ausente, ${ }^{14}$ e que o contato entre os interactantes da conversação se reduz a toques no teclado de uma máquina, com novas relações de poder, ao mesmo tempo que os espaços de contato se ampliam, alcançando interações em espaços (quartos, ${ }^{15}$ banheiros, escritórios) normalmente reservados para a intimidade, a solidão ou o trabalho profissional?16

A respeito das novas relações de poder que se estabelecem no ciberespaço, e que são fonte de discursos intolerantes, Catherine Blaya (2019) considera que atualmente os "tecno-poderosos" são aqueles individuos jovens (principalmente adolescentes) que possuem os conhecimentos tecnológicos e informáticos e as habilidades digitais (tais como práticas de publicação, difusão, referência e intercâmbio), além dos condicionamentos sociológicos tradicionais no mundo offline (a classe social, o gênero ou a origem étnica). O problema dos discursos intolerantes na rede é singular pelo motivo de que, ao contrário das situações offline em que esses discursos geralmente são tão violentos quanto fugazes, na rede, em vez disso, são duráveis, rastreáveis e são caracterizados por uma grande interatividade (viralização, curtidas). ${ }^{17}$

Ilustrando o conjunto das reflexões precedentes, a presente edição conta com dezoito artigos. Em "Tonos intolerantes en discursos de grandes medios de comunicación brasileños: un estudio dialógico", Maria da Glória Corrêa di Fanti e Juan Manuel López-Muñoz analisam discursos intolerantes contra a presidenta Dilma Rousseff, à época do processo de impeachment, veiculados na revista Isto É e no jornal Folha de S. Paulo. Na sequência, Luis Henrique Boaventura e Ernani Cesar de Freitas, em "Encenação e ubiquidade no Twitter: a intolerância dos discursos sobre Marielle Franco", investigam uma troca linguageira no Twitter acerca do assassinato de Marielle Franco e Anderson Gomes em 14 de março de 2018.

No artigo "Minions nas telas e bolsominions na vida: uma análise bakhtiniana", Luciane de Paula

\footnotetext{
14 "O digital frequentemente se associa a práticas 'sem rosto', mas o anonimato dos usuários não significa que o agressor e a vítima não se conhecem", precisa C. Blaya (2012), em Cyberharcèlement et climat scolaire: les premières données de l'enquête. Disponivel em: http:// www.touteduc.fr/fr/archives/id-5848-cyberharcelement-et-climat-scolaire-les-premieres-donnees-de-l-enquete-de-c-blaya. Acesso em: 10 mar. 2020.

15 Veja o conceito de Bedroom culture em Mari-Anne Paveau (2016, p. 13). Disponivel em: https://hal.archives-ouvertes.fr/hal-01423473/ document. Acesso em: 10 mar. 2020.

16 Cécile Dolbeau-Bandin (2017) fala dos casos de efeito de cabine (cockpit), baseando-se na analogia com os pilotos de combate que, em uma cabine protegida e longe do alvo, não percebem diretamente os danos causados. A autora cita, a esse respeito, o Rapport Cyberharcèlement: Risque du virtuel, impact dans le réel do Observatoire des Droits de l'Internet, 2009, p. 17. Disponivel em: http://economie.fgov.be/fr/binaries/Boekcyberpestenfr_tcm326-271185.pdf; https://www.mesdatasetmoi-observatoire.fr/article/parlons-enfin-de-cyberharcelement\#anchor13. Acesso em: 10 mar. 2020.

${ }_{17}$ Os discursos intolerantes na rede se caracterizam pela velocidade e a viralização com que podem se espalhar, com o simples gesto de um único clique. Os discursos intolerantes podem ser transmitidos, "curtidos" e compartilhados milhares de vezes. E pior ainda, eles são duradouros, podendo perseguir a vítima muito depois do fato. Veja, entre outros, Cécile Dolbeau-Bandin. Disponível em: https:// www.mesdatasetmoi-observatoire.fr/article/parlons-enfin-de-cyberharcelement\#anchor13. Acesso em: 10 mar. 2020.
} 
e Natasha Ribeiro de Oliveira refletem a respeito do termo "bolsominion" no Facebook, observando a articulação entre discurso, vida e arte. Tamiris Machado Gonçalves, em "Charge com contorno intolerante: uma análise discursiva", analisa uma charge de Roque Sponholz, veiculada em 2011, na mídia digital brasileira. Já Evandra Grigoletto e Thiago Alves França, no artigo "Discursos de resistência à intolerância pela censura: o caso da propaganda do Banco do Brasil", analisam a intolerância por meio da polêmica gerada por uma peça publicitária, cuja exibição oficial foi impedida pelo presidente Jair Bolsonaro.

Em "Fake news e pós-verdade na construção do Neoconservadorismo no Brasil pós-2013 e os efeitos nas eleições de 2018", Mauri de Castro Azevedo e Marcus Antônio Assis Lima discutem o crescimento das ideias extremistas na sociedade brasileira por efeito da difusão massiva de notícias falsas e de discursos políticos intolerantes nas redes sociais nas últimas eleições para presidente. Também se ocupam das redes sociais Marcelo Vinicius Costa Amorim e Antônio Fernandes Júnior que, em "(Diz)positivo para matar: uma análise sobre o discurso de ódio no Brasil contemporâneo", estudam a arqueogenealogia dos discursos de ódio e seus efeitos nos processos de subjetivação.

Contemplando questões de gênero, por um lado, Bruna Vitória Tejada e Luciana lost Vinhas, em "Aquilo que não pode deixar de ser dito: o efeito de pré-construído do discurso machista", investigam a noção de pré-construido sob a ótica da Análise de Discurso de tradição francesa. Por outro Lado, Fábio Luiz de Castro Dias, Marina Alvarenga Botelho e Marco Antonio Villarta-Neder, no artigo "A violência da palavra em ausência no processo discursivo de representação das mulheres: uma análise do Projeto de Lei 0100352/2019", analisam a representação da mulher em Projeto de Lei da Câmara Municipal de São Paulo. Por sua vez, Martha Júlia Martins de Souza, em "Feminismo e intolerância: uma análise das leis estaduais do estado de Roraima", discute questões de gênero no âmbito escolar a partir das leis 1245/2018 e 1323/2019.
No artigo "Documentos jurídicos, 'cura gay' e legitimação do heterossexismo: uma análise discursiva do PDC 234/2011", Gabriel Merlim Moraes Villela, Maria Cristina Giorgi, Fabio Sampaio de Almeida e Dayala Paiva de Medeiros Vargens investigam a função que desempenham documentos juridicos ao legitimar certas práticas heterossexistas que alimentam discursos de ódio e intolerância. Welton Pereira e Silva, em "Discursos criminalizáveis: proposta de conceituação a partir de cartas de ameaça", volta-se para os imaginários sociodiscursivos que embasam a argumentação intolerante presente em duas cartas de ameaça com motivação homofóbica. No artigo "Discursos políticoreligiosos como armas de guerra: heteroterrorismo em ação contra sexualidades dissidentes", Alexandre de Oliveira Fernandes e Luciano Fernandes de Souza sustentam que a interpelação, em discursos políticoreligiosos extremistas, inscreve os dissidentes sexuais em um cenário de heteroterrorismo.

A questão da liberdade e da autonomia das escolas, dos alunos e dos professores frente ao Projeto de Lei Escola Sem Partido (PL 7.180/2014) está na origem do artigo assinado por Rosely Diniz da Silva Machado e Letícia Rosaura da Silva Maass com o título "We don't need no education: Escola Sem Partido de quem e para quem?" Por sua vez, Ilmara Valois Bacelar Figueiredo Coutinho, em "Reflexões sobre leitura e ensino no Brasil em tempos de pós-verdade", reflete sobre o desafio da formação leitora nos tempos atuais, defendendo o ensino da leitura como ato político, ao permitir pensamentos críticos em relação às contradições sociais contemporâneas.

Em "Temperança de Tonus: agora vai ser assim contra a intolerância", Daniel de Oliveira Gomes estabelece uma relação entre a poesia de Leonardo Tonus com a figura da Temperança, do Tarot, inspirando-se nos trabalhos de Milton Santos e Zigmunt Bauman. Elisa Marchioro Stumpf, em "Eufemismo: um fenômeno multifacetado no cruzamento entre língua e cultura", focaliza temas como a (des)cortesia e a violência verbal. Por fim, Ana Raquel Motta, no artigo "'Comunicação nãoviolenta' pelas lentes da Linguistica: embates no combate à intolerância", destaca a contribuição 
dos estudos linguísticos para o desenvolvimento da noção de comunicação não violenta.

Além dos artigos mencionados, o presente número inclui duas resenhas. Por um lado, Luiz Augusto Ely apresenta uma recensão da obra Análisis del discurso, disciplina interpretativa en interdisciplinariedad: violencia y estudios ético-politicos de los discursos, organizada por Graciana Vázquez Villanueva e Pablo von Stecher e publicada pela Faculdade de Filosofia e Letras da Universidade de Buenos Aires em 2019. Por último, Baal Ulises Delupi resenha o livro coletivo Politica prática, organizado por Everton Maciel, Sergio Corrêa e Tiaraju Andreazza e publicado pela Universidade Federal do Amapá em 2020.

O conjunto dos trabalhos aqui apresentados estimula o debate eadvoga a reconstrução da ordem social, segundo o postulado por Mouffe (2010), com o objetivo de contribuir para a implementação de uma democracia plural, resistente diante das práticas discursivas intolerantes. Em resumo, com esta edição da Letrônica, defendemos a importância do respeito à diversidade de posicionamentos e de modos de viver, sem impedir a discussão nem silenciar as contradições.

\section{Referências}

ASSOULINE, Pierre. La métamorphose du lecteur. Le Débat, n. 170, p. 78-89, 2012. https://doi.org/10.3917/ deba.170.0078

BALANDIER, Georges. Le Détour: Pouvoir et modernité. Paris: Fayard, 1985.

BLAYA, Catherine. Les jeunes et la violence sur Internet. Paris: Éditions Nouveau Monde, 2019.

BLAYA, Catherine. Cyberharcèlement et climat scolaire: les premières données de l'enquête. ToutEduc, 2012. Disponivel em: http://www.touteduc.fr/fr/archives/id-5848-cyberharcelement-et-climat-scolaire-les-premieres-donnees-de-l-enquete-de-c-blaya.

BUTLER, Judith. Lenguaje, poder e identidad. Madrid: Sintesis, 2009

CARRERA, Oscar. Mitología humana. Madrid: Ápeiron Ediciones, 2019.

CARRILLO DONAIRE, Juan Antonio. La protección de los derechos frente a los discursos del odio: del derecho represivo a las políticas públicas antidiscriminatorias. In: ALONSO, L.; VÁZQUEZ, V. (dir.). Sobre la libertad de expresión y el discurso del odio. Sevilla: Athenaica, 2017. p. 15-38.
CONSEIL DE L'EUROPE. 23.XI.2001. Convênio sobre la ciberdelincuencia. Disponivel em: https://www.oas. org/juridico/english/cyb_pry_convenio.pdf. Acesso em: 03 jan. 2020.

CONVENIO SOBRE LA CIBERDELINCUENCIA. 2001. Disponivel em: https://Www.oas.org/juridico/english/ cyb_pry_convenio.pdf. Acesso em: 03 de jan. 2020.

CONVENCIÓN INTERAMERICANA CONTRA TODA FORMA DE DISCRIMINACIÓN E INTOLERANCIA. 2013. Disponivel em: http://www.oas.org/es/sla/ ddi/docs/tratados_multilaterales_interamericanos_A-69_discriminacion_intolerancia.pdf. Acesso em: 03 jan. 2020.

DOLBEAU-BANDIN, Cécile. Parlons (enfin) de cyberharcèlement!, L'Observatoire, mesdatasetmoi.fr, 05/10/2017. Disponivel em: https://www.mesdatasetmoi-observatoire.fr/article/parlons-enfin-de-cyberharcelement\#anchor13. Acesso em: 03 jan. 2020.

IMBLEAU, Martin. La négation du génocide nazi, liberté d'expression ou crime nazi? Le négationnisme de la Shoah en droit international et comparé. Paris: Budapest, Turin, l'Harmattan, 2003.

JULLIEN, François. Il n'y a pas d'identité culturelle. Paris: l'Herne, 2016.

JULLIEN, François. L'écart et l'entre. Paris: Galilée, 2012.

JULLIEN, François. De l'universel, de l'uniforme, du commun et du dialogue entre les cultures. Paris: Fayard, 2008.

LAGADEC, Patrick. Risque technologique majeur - Politique et processus de développement. Paris: Pergamon, 1981.

LÓPEZ-MUÑOZ, Juan Manuel. Identidad y lengua en el ciberespacio: ¿existe una conciencia lingüistica digital? Gragoatá, v. 24, n. 48, p. 117-135, 2019. https:// doi.org/10.22409/gragoata.v24i48.33622

MANUAL CÓMO CONTRARRESTAR EL DISCURSO EL DISCURSO DE ODIO EN LÍNEA. 2015. Disponivel em: https://unesdoc.unesco.org/ark:/48223/ pfo000233231. Acesso em: 03 jan. 2020.

MOUFFE, Chantal. Politique et agonisme. Rue Descartes, v. 67, n. 1, 2010, p. 18-24. https://doi. org/10.3917/rdes.067.0018

MOUFFE, Chantal. On the political, Abingdon. Nueva York: Routledge, 2005.

MOUFFE, Chantal. The democratic paradox. Londres: Verso, 2000.

MOULAY, Maurice \& REBISCHUNG, Thomas. Comprendre l'émotion, Paris: MaxMilo, 2011.

PAVEAU, Mari-Anne. Éthique du discours numérique. Linguas e Instrumentos Linguisticos (Brésil), RG Editora, 2016, 37, p.177-210. Disponivel em: https://hal. archives-ouvertes.fr/hal-01423473/document.

SICARD, Marie-Noële. Entre médias et crises technologiques: les enjeux communicationnels. Paris: Presses Universitaires du Septentrion, 1998. 
SZUNDY, Paula; CARRĖRA, Tatianne; NASCIMENTO, Luciana Marino. Leitores-navegantes de textos e hipertextos da literatura. Gragoatá, n. 40, v. 1, p. 354379, 2016

WEBER, Anne. September 2009. Manual on hate speech. Disponivel em: http://icm.sk/subory/Manual_on_hate_speech.pdf. Acesso em: 03 jan. 2020.

ZUBERO, Imanol. La identidad cultural no existe. Madrid: Taurus, 2017.

\section{Juan Manuel López-Muñoz}

Doutor em Filologia Francesa pela Universidad de Cádiz e professor titular do Departamento de Filologia Francesa e Inglesa da Faculdade de Filosofia e Letras da Universidad de Cádiz.

\section{Maria da Glória Corrêa di Fanti}

Doutora em Linguística Aplicada e Estudos da Linguagem pela Pontifícia Universidade Católica de São Paulo (PUCSP, São Paulo, SP, Brasil) e professora-pesquisadora do Programa de Pós-Graduação em Letras da Escola de Humanidades da Pontifícia Universidade Católica do Rio Grande do Sul (PUCRS, Porto Alegre, RS, Brasil). Bolsista de Produtividade em Pesquisa do CNPq.

\section{Bárbara Luzia Covatti Malcorra}

Doutoranda em Letras pela Pontificia Universidade Católica do Rio Grande do Sul (PUCRS, Porto Alegre, RS, Brasil). Bolsista CNPq. Mestre em Letras pela mesma instituição. Licenciada em Letras com habilitação Português e Inglês pela Universidade do Vale do Rio dos Sinos (UNISINOS, São Leopoldo, RS, Brasil).

\section{Endereço para correspondência}

Juan Manuel López-Muñoz

Universidad de Cádiz

Facultad de Filosofía y Letras - Departamento de Filologia Francesa e Inglesa

Av. Dr. Gómez Ulla, 1

Cádiz, 11003

Espanha

Maria da Glória Corrêa di Fanti/ Bárbara Luzia Covatti Malcorra

Pontificia Universidade Católica do Rio Grande do Sul

Escola de Humanidades - Programa de Pós-Graduação em Letras

Av. Ipiranga, 6681, Prédio 8

Partenon, 90619-900

Porto Alegre, RS, Brasil 